\title{
Clinical performance of removable partial dentures: A retrospective clinical study
}

\author{
Maged K. Etman ${ }^{*}$, Darya Bikey ${ }^{2}$ \\ ${ }^{1}$ Division of Prosthodontics, College of Dentistry, University of Saskatchewan, Saskatoon, Canada \\ ${ }^{2}$ Mount Sinai Hospital, University of Toronto, Toronto, Canada \\ Email: ${ }^{*}$ maged.etman@usask.ca
}

Received 1 July 2012; revised 10 August 2012; accepted 21 August 2012

\begin{abstract}
Removable partial dentures (RPDs) (conventional and implant-supported) treatment is considered a viable option to replace missing teeth as inexpensively as possible, but it has limitations. Objectives: This study reports the effect of gender and location (maxilla vs. mandible) on the clinical performance of removable partial dentures (RPDs). Materials and Methods: A total of 100 Patients who had RPDs delivered between 1990-1995 were evaluated. A 4-point scoring system was used to assess seventeen criteria. These criteria include acceptance, stability, support, retention, adaptation, occlusion, integrity, and design of the prostheses, rest and rest seat preparation, occlusal wear, esthetics, phonetics, tissue condition, mobility of abutments, gingival and plaque indices. The data were analyzed using Kruskal-Wallis and Mann-Whitney U non-parametric statistical tests. Results: The results showed that acceptance of RPDs was rated the lowest. Other reasons for failure were poor retention, lack of integrity of the prostheses and inadequate adaptation. Retention and design of major connectors attributed to Mandibular RPD failure. Success rate of $75 \%$ was observed in male compared with $67.2 \%$ for female. Maxillary RPDs showed a higher success rate $\mathbf{( 7 8 \% )}$ compared with the mandibular $(\mathbf{7 0 . 1 \% )}$. No significant statistical difference in Alpha scores between female and male patients and between maxillary and mandibular RPDs $(p<0.05)$. Conclusions: The clinical performance of RPDs showed a higher success rate in male patients compared to female patients and the maxillary RPDs showed a higher success rate compared to mandibular.
\end{abstract}

Keywords: Clinical Performance; Removable Partial Denture; Maxilla; Mandible; Gender

${ }^{*}$ Corresponding author.

\section{INTRODUCTION}

There is an increasing proportion of the elderly population that is retaining some natural teeth and this number will continue to grow, at least in the short-term [1]. Although tooth loss will be reduced, prosthetic replacement of missing teeth is unlikely to entirely disappear [2]. There will be an increase in unmet prosthodontics need [3]. Several options are available for prosthetic rehabilitation such as conventional fixed and removable prosthodontics and dental implant supported/retained prostheses.

Dental implants are becoming more common and are rapidly becoming the standard of care in dentistry [4-9]. It is important to realize that conventional fixed prostheses and dental implants have limitations [8-10]. A major obstacle to these treatment options is the financial consideration which may preclude some patients from receiving these treatments. For some patients needing to replace missing teeth as inexpensively as possible, conventional and implant-supported removable partial prosthetic treatment may be the most viable option. The data from the published reports suggest that the incorporation of dental implants into removable partial dentures could be an optional treatment plan for the partially edentulous patient to improve function and patient satisfaction [1113].

A careful assessment of patient compliance regarding oral hygiene and routine maintenance should be completed before considering rehabilitation using RPDs [14]. The overall success rates of RPDs as reported in the literature are at a respectable level. One study found a $71.3 \%$ success rate for RPDs with a circumferential clasp design and $76.6 \%$ success rate for RPDs with an I-bar clasp design after 5 years of usage [15]. A different study, which defined failure as the patient not wearing the original RPD, reported $74.7 \%$ of patients were still wearing their RPDs [16]. The authors divided RPDs usage into 5 year intervals. They reported success rate of $85.7 \%$ for 5 - 10 years period, $62.8 \%$ for $10-15$ years 
period, and $57.1 \%$ for over 15 years period. Other researchers evaluated RPDs with an average 2.5 years of service and found $43 \%$ of RPDs to be acceptable and $46 \%$ could be made acceptable with modifications, such as a reline or adjustment [17]. As is evident in the literature, success rates of RPDs are reasonable and they remain a justifiable option for the treatment of partially edentulous patients [18].

Although a vast number of RPDs are fabricated, there is a shortage of current research that attempts to study RPDs over an extended time period. Moreover, there is a shortage of clinical studies closely investigating the effects of gender and location (maxilla vs. mandible) on RPD success rates. An article published on gender difference regarding oral health found differences in chief complaints between elderly males and females [19]. Males appeared to demand that dentures improve their mastication, whereas the concerns of females centered on problems related to pain, hypersensitivity and esthetics. The results from another study on RPDs revealed no significant difference in general satisfaction between males and females, aside from men being less satisfied with the mastication with lower RPDs [20]. A review of the literature also fails to produce evidence comparing the success rates of maxillary and mandibular RPDs. One study reported patient satisfaction to be equal between maxillary and mandibular RPDs, however, the authors found a significant difference in failure rates between maxillary and mandibular RPDs [16]. In that study, the failure rate for mandibular RPDs was 33\% compared to $12.7 \%$ for maxillary RPDs. Another study showed greater patient compliance with maxillary RPDs possibly due to esthetics and comfort [21]. Despite the fact that RPD fabrication is not becoming an obsolete treatment modality, there currently appears to be a decreasing focus on this subject area in the literature. It was expected that gender and location of RPD would have no effect on the success rate of the prosthesis. Expanding the knowledge about the long-term success rates of RPDs and the influences of gender and intra-oral location would be advantageous to both practitioners and patients alike. Consequently, the main objective of this study was to evaluate the effect of gender and intra-oral location on the clinical performance of RPDs over a 15-year time period in a university setting.

\section{MATERIALS AND METHODS}

Patient population for this retrospective study were selected from the patient pool at a university setting following certain criteria. These criteria include: only class 1 (philosophical) and 2 (exacting) patients according to House's psychological classifications, patients who have had at least one RPD delivered between 1990-1995, no parafunctional habits, no known disabilities that may have an effect on RPD maintenance, opposing natural teeth, and a history of patient compliance to follow post-delivery instructions with regular attendance for maintenance. Ethics approval was obtained from the Biomedical Research Ethics Board. One hundred patients who had their prostheses delivered between 1990-1995 were randomly selected using a random table created using a SPSS statistical program (SPSS 16.0.2, Chicago, IL, USA). The demographic distribution of patient's population and RPDs are represented in Table 1. Patients were enrolled and scheduled for a clinical examination. Patients were informed and a patient information sheet was given to each patient, also consent was obtained from each patient. In addition, medical and dental history was updated along with any other pertinent information. Two calibrated assessors conducted all the examinations. Radiographs were taken for all the RPD abutments, and the radiographs were compared with previous radiographs. A four-point scoring system (Alpha, Bravo, Charlie, Delta was used (Table 2) to evaluate each of 17 criteria. Each criterion was rated according to a predetermined definition (Table 3). Although the assessment was subjective, having two calibrated assessors complete all the examinations allowed consistency.

Before beginning the examination, patients were asked about their satisfaction level with the prostheses. This is a very important criterion and does not always correlate with the outcomes score from other criteria. Patients with positive attitude towards their RPDs could function satisfactorily even though their RPDs were poorly designed;

Table 1. Demographic distribution of study subjects. (KC: Kennedy Classification).

\begin{tabular}{|c|c|c|c|c|c|c|c|c|}
\hline & \multicolumn{8}{|c|}{ Demographic Distribution } \\
\hline & \multicolumn{2}{|c|}{ Gender } & \multicolumn{2}{|c|}{ Location } & \multicolumn{4}{|c|}{ Age } \\
\hline & Male & Female & Maxillary & Mandibular & \multicolumn{2}{|c|}{ Male $\mathrm{N}=47$} & \multicolumn{2}{|c|}{ Female $\mathrm{N}=53$} \\
\hline & 47 & 53 & 50 & 67 & $21-40$ & 13 & $21-40$ & 12 \\
\hline & $\begin{array}{l}\text { KCI: } 28 \\
\text { KCII. } 23\end{array}$ & $\begin{array}{l}\text { KCI: } 26 \\
\text { KCII } 20\end{array}$ & $\begin{array}{l}\text { KCI: } 23 \\
\text { KCII. } 19\end{array}$ & $\begin{array}{l}\text { KCI: } 31 \\
\text { KCII. } 24\end{array}$ & $41-60$ & 18 & $41-60$ & 20 \\
\hline & KCIV: 9 & KCIV: 11 & KCIV: 8 & KCIV: 12 & $61-80$ & 10 & $61-80$ & 13 \\
\hline & & & & & $81-100$ & 6 & $81-100$ & 8 \\
\hline Total & \multicolumn{2}{|c|}{ Number of patients: 100} & \multicolumn{2}{|c|}{ Number of RPDs: 117} & Average age & 55 & Average age & 58 \\
\hline
\end{tabular}


Table 2. 4-point scoring system used to assess each criterion.

\begin{tabular}{cc}
\hline Scoring Scale & Description \\
\hline $\mathrm{A}=$ Alpha & Excellent, RPD clinically ideal \\
$\mathrm{B}=$ Bravo & $\begin{array}{c}\text { Clinically acceptable, RPD with changes } \\
\text { that are clinically acceptable }\end{array}$ \\
$\mathrm{C}=$ Charlie & RPD with changes that require intervention \\
$\mathrm{D}=$ Delta & Unacceptable, replacement necessary \\
\hline
\end{tabular}

Table 3. 17 criteria for evaluation of RPDs.

\begin{tabular}{|c|c|}
\hline Criteria & Definition \\
\hline $\begin{array}{l}\text { Patients acceptance } \\
\text { of prosthesis }\end{array}$ & Patient satisfaction level with RPD \\
\hline Stability & $\begin{array}{l}\text { Movement of RPD on alveolar ridge } \\
\text { when vertical pressure applied } \\
\text { unilaterally }\end{array}$ \\
\hline Support & $\begin{array}{l}\text { The resistance to displacement } \\
\text { towards the tissues when applying } \\
\text { vertical pressure }\end{array}$ \\
\hline Retention & $\begin{array}{l}\text { Vertical resistance of RPD when } \\
\text { applying force to remove denture }\end{array}$ \\
\hline Adaptation & $\begin{array}{l}\text { Adaptation of clasp assembly, major/ } \\
\text { minor connectors, and denture base }\end{array}$ \\
\hline Occlusion & $\begin{array}{l}\text { Presence of adequate number of } \\
\text { contacts with an even distribution } \\
\text { in centric occlusion }\end{array}$ \\
\hline Integrity of prosthesis & Integrity of prosthesis structure \\
\hline Rests and rest seats & Design of rests and rest seats \\
\hline Major connector design & Design of major connector \\
\hline Minor connector design & Design of minor connector \\
\hline Occlusal wear & Wear of teeth on occlusal surface \\
\hline Esthetics & $\begin{array}{l}\text { Evaluation of esthetics (shade, } \\
\text { morphology, position, size, } \\
\text { and clasp visibility) }\end{array}$ \\
\hline Phonetics & $\begin{array}{l}\text { Assessment of speech problems by } \\
\text { asking patient to say words with } \\
\text { letters "p", "b", "f", "v", and "s" }\end{array}$ \\
\hline Tissue evaluation & $\begin{array}{l}\text { Abnormal color and swelling on } \\
\text { denture bearing surface }\end{array}$ \\
\hline Mobility evaluation & Detecting tooth mobility of abutments \\
\hline Gingival index & $\begin{array}{l}\text { Clinical severity of gingival } \\
\text { inflammation }\end{array}$ \\
\hline Plaque index & Level of plaque accumulation \\
\hline
\end{tabular}

whereas patients who have poor attitude toward their RPDs may not be satisfied even with excellent or acceptable RPDs. Thus, although the other criteria are important, patient acceptance is an absolutely critical.

Stability of the prosthesis was determined by the amount of movement observed when moderate unilateral apically directed pressure was applied on the occlusal surface of the RPD. This movement was recorded in millimetres. Likewise, with Kennedy Class IV RPDs, moderate apically directed pressure was applied to the incisal surface of the replacement teeth of the RPD and any movement observed was recorded. Support for the prosthesis was evaluated by applying bilateral vertical pressure apically and determining the resistance to displacement towards the tissues. Retention was assessed by determining the force required to vertically displace and remove the RPD away from the alveolar ridge. The assessors would remove the RPD using both hands by applying bilateral force directed coronally along the path of insertion of the prosthesis. The adaptation of RPD components, such as major connectors, minor connectors, direct and indirect retainers, and the denture base were determined visually and by an explorer and probing instrument. In order to assess occlusion, each patient was asked to repeat jaw movements several times. Centric and eccentric movements of each subject were examined by marking contacts with articulating paper. Occlusion was considered clinically acceptable when the RPD was stable and a free gliding movement $(2-3 \mathrm{~mm})$ without cuspal interference during these actions was observed $[22,23]$. Integrity of the prostheses was evaluated visually for any structural defects. Evaluation of rests and rest seats, major and minor connectors design and abutment teeth were carried out according to standard protocol [24]. Any design characteristics, such as inappropriate position of rest seats, inadequate preparation of rest seats, inappropriate minor and major connector design selection were recorded.

Occlusal wear of acrylic teeth of RPDs was evaluated visually and was compared to wear of the patient's natural dentition. The aesthetics of RPDs replacing anterior teeth was assessed according to the shade, morphology, position, size of the anterior teeth, and proper lip support as well as inspecting visibility of the for clasp. Phonetics with RPDs was evaluated, but was more critical in Kennedy Class IV arches. The patient was asked to repeat words that emphasized the letters "p", "b", "f", "v", and "s" and any irregular sounds or difficulties with these words were recorded. The abutment teeth and the attached mucosa (quality and quantity) were evaluated. Tissue evaluation was based on determining the quality and quantity of the attached mucosa, which are indicative of supporting structures of the denture-bearing surface.

Also, the presence of inflammation, ulceration, or any other denture-related pathology on the denture bearing area was recorded. Tooth mobility was evaluation by manual inspection of abutment and non-abutment teeth. The data were analyzed using Kruskal-Wallis and MannWhitney U non-parametric statistical tests using a SPSS statistical program.

\section{RESULTS}

Success rates of the RPDs were based on calculating the percentage of Alpha, Bravo and Charlie scores from the 
raw data. All the data were comprised of the evaluations of the calibrated assessors except patient acceptance. Patient acceptance involved the patient's input in relation to other criteria, such as stability, retention, esthetics, etc. Only the prostheses that had Delta ratings were considered failures. An overall $70.5 \%$ success rate was observed for the RPDs over 15-year period. In general, failure of RPDs was mainly due to patient acceptance, poor retention, integrity of the prostheses and adaptation (Figures 1 and 2).

A $75 \%$ success rate was observed in male patients compared with $67.2 \%$ for female patients and for both genders patient acceptance of RPDs was rated the lowest among all the criteria. In male patients $23 \%$ of acceptance ratings were given Delta scores, mainly because these patients either found they were not able to adapt to wearing the RPD(s) or found they functioned sufficiently without the prosthesis. As seen in Figure 3, the other criteria with the highest Delta scores in male patients were adaptation and occlusion. In female patients $25 \%$ of acceptance ratings were given Delta scores, which in most cases was due to their perception of undesirable esthetics and poor retention, even though these criteria were assessed as acceptable to excellent during the com- prehensive examination. Figure 4 portrays the other criteria with the highest Delta scores in females, they include: retention, adaptation, integrity of prosthesis, rests and rest seats, and major connector design. Statistical analysis showed no significant difference in Alpha scores between female and male patients.

The maxillary RPDs showed a higher success rate of $78 \%$ compared with $70.1 \%$ in mandibular RPDs. Similarly, the patient acceptance criteria was rated the lowest for both maxillary and mandibular RPDs. $22 \%$ of acceptance ratings of maxillary RPDs were given Delta scores mainly due to improper adaptation of the RPD as patient was complaining from discomfort and food impaction. The other criteria with high Delta scores among maxillary RPDs were integrity of the prosthesis and major connector design (Figure 5). On the other hand, mandibular RPDs had $25 \%$ of their acceptance ratings given Delta scores as a result of patients not being able to adapt to wearing the RPD, even though these RPDs were generally assessed as acceptable or excellent. The other criteria with high Delta scores among mandibular RPDs were adaptation and retention (Figure 6). Statistical analysis showed no significant statistical difference in Alpha scores between maxillary and mandibular RPDs $(\mathrm{p}<0.05)$.

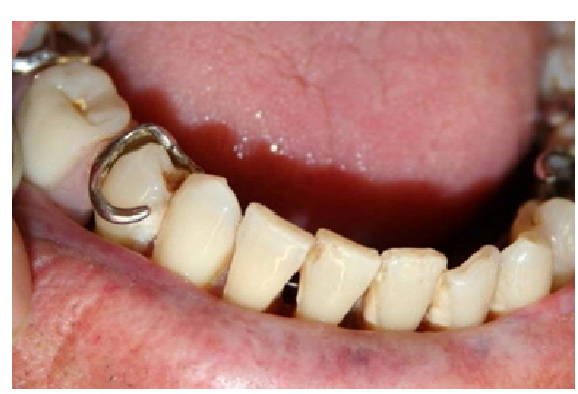

(a)

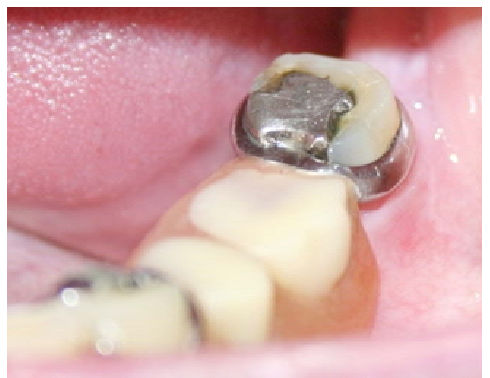

(b)

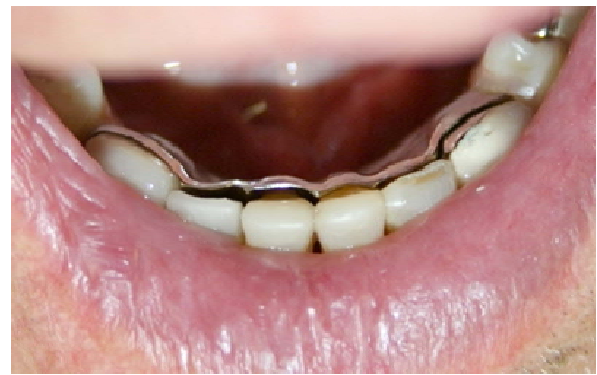

(c)

Figure 1. (a) Mandibular RPD demonstrating poor adaptation of direct retainer clasp; (b) Mandibular RPD with fractured rest and severe occlusal wear; (c) Mandibular RPD with poor adaptation of lingual plate major connector.

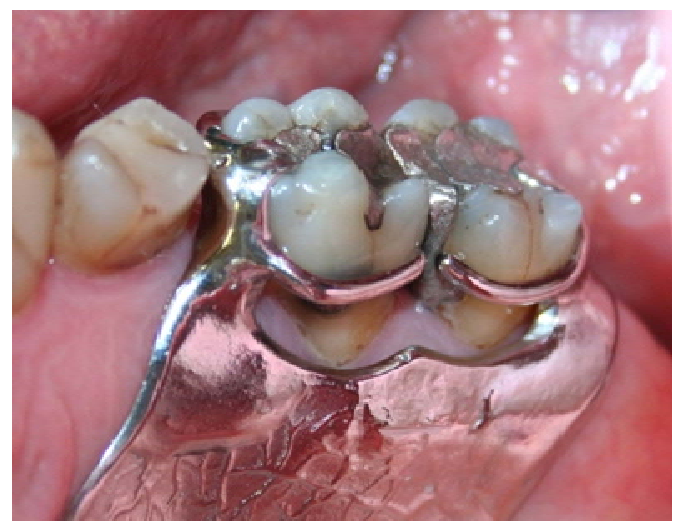

(a)

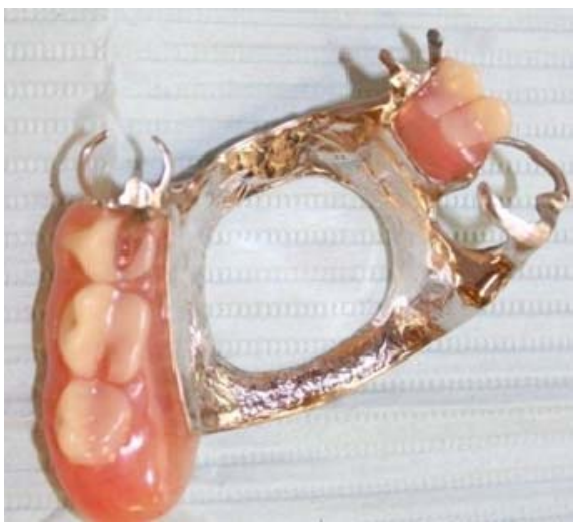

(b)

Figure 2. (a) Maxillary RPD with impingement on tissues leading to gingival recession; (b) Maxillary RPD with severe occlusal wear. 


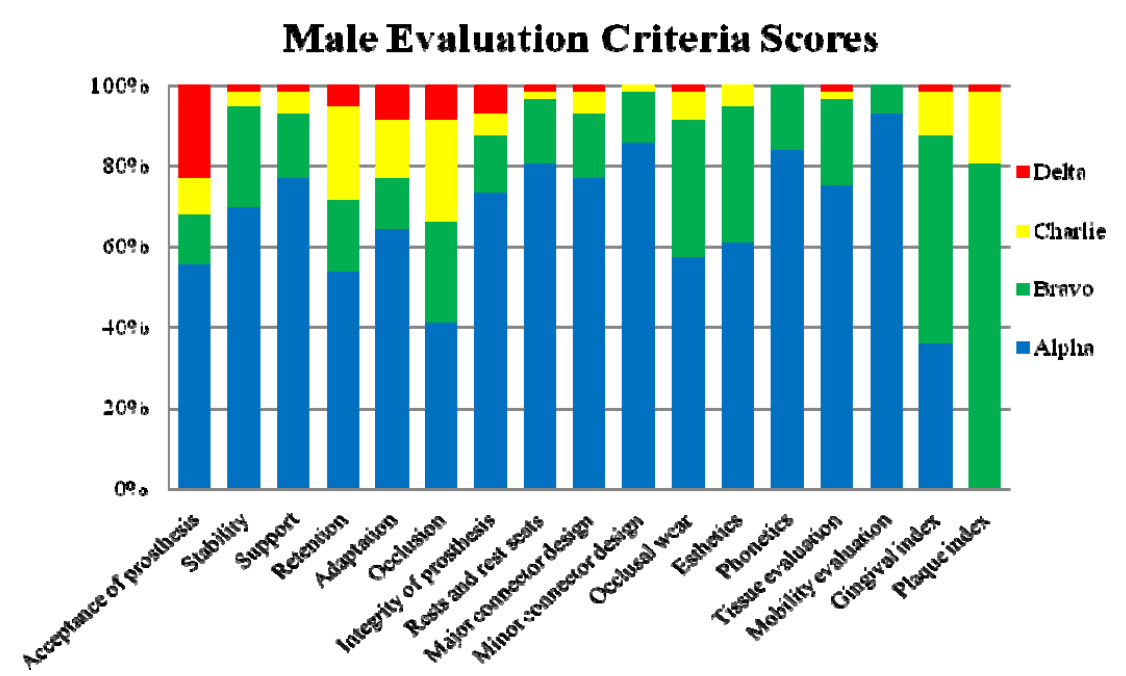

Figure 3. Male evaluation scores for the 17 criteria assessed.

\section{Female Evaluation Criteria Scores}

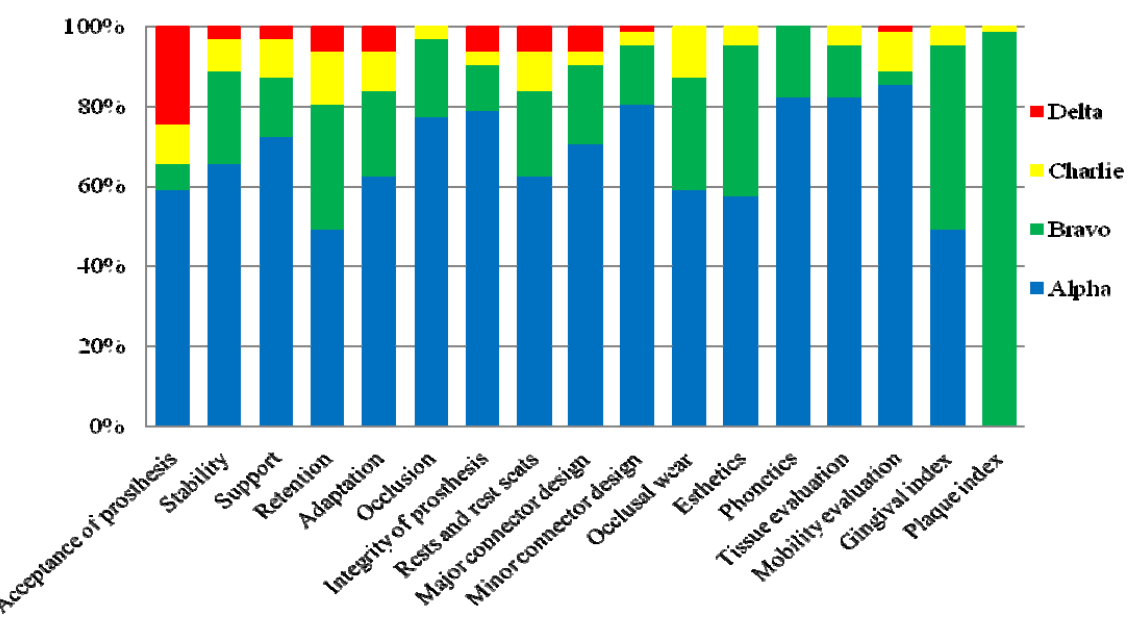

Figure 4. Female evaluation scores for the 17 criteria assessed.

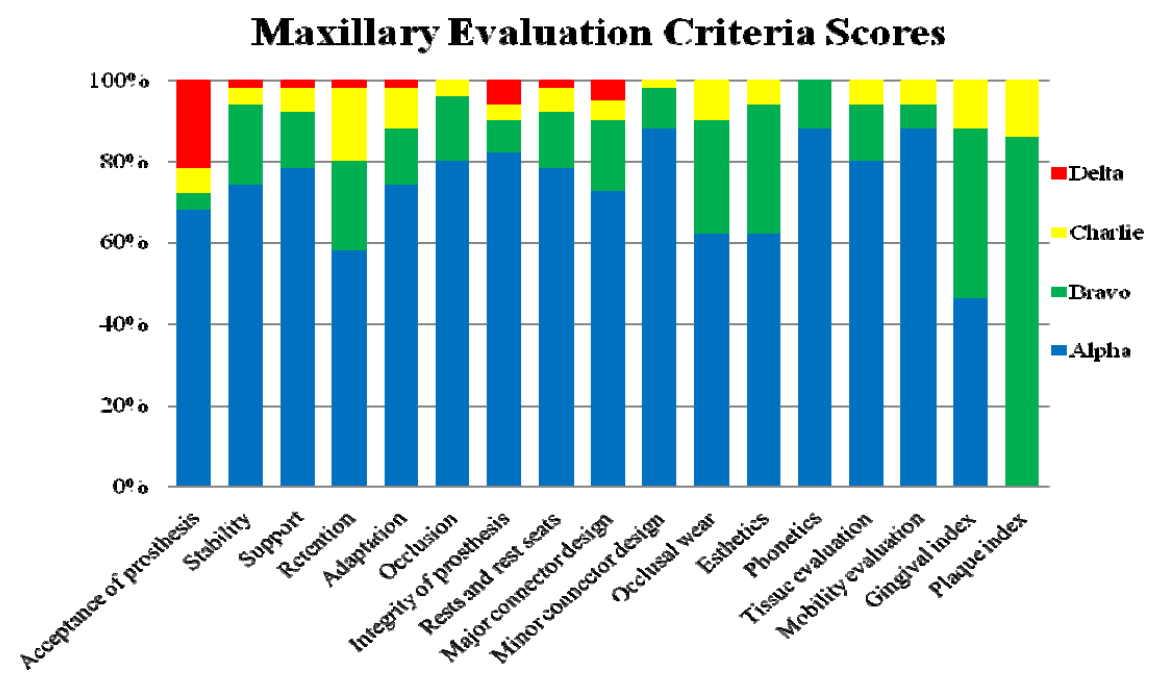

Figure 5. Maxillary evaluation scores for the 17 criteria assessed. 


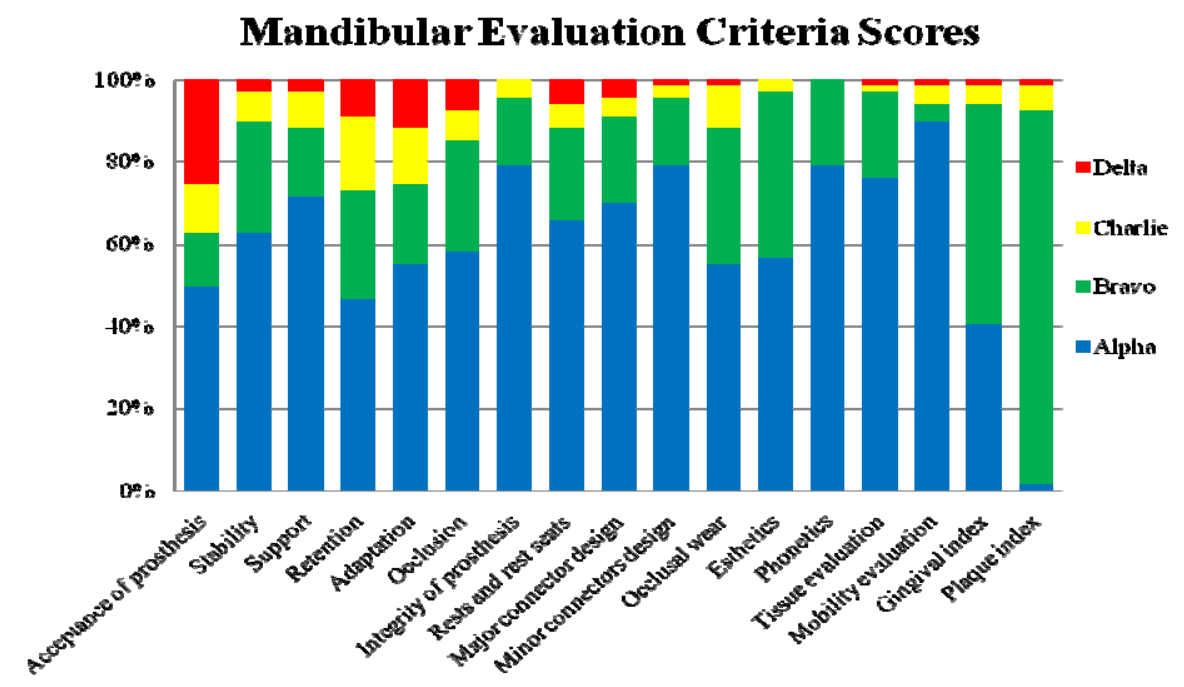

Figure 6. Mandibular evaluation scores for the 17 criteria assessed.

\section{DISCUSSION}

There is a shortage of clinical performance studies on RPDs that further investigate the influence of factors such as gender and intra-oral location. The purpose of this research was to report on the effect of gender and intra-oral location on the clinical performance of RPDs. These findings in turn may have ramifications on the manner in which dentist's evaluate treatment of partially edentulous patients with RPDs.

It must be noted that the evaluation of the criteria for this study contains a degree of subjectivity because of the somewhat subjective nature of clinical evaluations of dental prostheses. Utilizing two Calibrated Assessors however, allowed for maintaining a high level of consistency in the clinical evaluations. The nature of the study performed, a retrospective clinical study, must also be taken into consideration when interpreting the findings. Retrospective studies are one approach used to surmise survival rates and the longevity of different restorative treatments. Unlike prospective studies that may have the same operator(s) complete both the treatment and the follow-up evaluations, the evaluator(s) in a retrospective study evaluate the treatment completed by a different operator or operators. Nonetheless, retrospective studies provide a valuable means to evaluate restorative treatments and illustrate the possible basis for their success and failure. Criteria for patient's selection were used to eliminate or to reduce factors that may affect the results of this study.

Success rates of the RPDs were calculated based on the percentage of Alpha, Bravo, and Charlie scores. The overall success rate of RPDs delivered by undergraduates between 1990 and 1995 with average 17 years in function was comparable with other RPD success rates in published studies [15-17]. In this study the Assessors evaluated the prostheses and patients were only asked for their level of satisfaction (i.e. acceptance) with their RPD(s). As reported by some clinicians, patients and dentists evaluate the success of RPD treatment differently [25]. Patients look upon success in terms of personal satisfaction, which differs from dentists who assess denture success in terms of specific technical and clinical standards. Our results agree with this finding and draw attention to disparities in gender. Among male patients examined it was observed that the chief concern raised was regarding their ability to chew with the prosthesis, despite the fact that there were other serious shortcomings with the prosthesis that affected the success rates. In female patients there was a lower acceptance of RPDs due to the perception of poor retention and undesirable esthetics, in spite of these criteria being evaluated as acceptable or excellent in most cases. Several studies have reported the level of satisfaction or the acceptance of RPDs to have a multi-causal or multi-dimensional character [26-31]. The present study confirms this finding, but it also highlights that each gender may have more particular, fundamental issues that influence acceptance and thereby influence overall success.

The failure scores in acceptance for male and female patients and maxillary and mandibular RPD patients was a major determinant in the resulting RPD success rates in this study. The findings indicate that males may have a slightly greater adaptability to a removable prosthesis than females and this may be linked to the overall slightly greater acceptance in males. It has been described that a slightly higher percentage of women reported having issues with their mandibular RPDs, but a significant relationship between gender and patient satisfaction with new RPDs was not encountered [32]. Conversely, studies on complete denture patients have 
shown women to be more likely to have problems accommodating to new dentures [33,34]. It appears women may be more likely to have problems adapting to their new RPD(s), resulting in lower acceptance of their prosthesis. The results of this study suggest that there is indeed a difference in the level of acceptance of RPDs between males and females, females having an overall lower acceptance, resulting in a lower success rate of RPDs in females.

There was a noticeable difference in the evaluation scores for occlusion between male and female patients; male patients having more failure scores. This finding is likely because males generate higher masticatory forces compared to females [35], thereby resulting in excessive wear and poor occlusion. Another relevant finding between males and females was in the design criteria scores; RPDs in females had greater failure scores for design. This result could be explained by the nature of the desires and expectations of female patients. Female patients would appear to have higher esthetic demands and concerns than males. Therefore, females may opt for improving esthetics at the risk of compromising the design of the prosthesis, whereas males may not be as concerned about the appearance of a component(s) of the prosthesis, as long as the function of the prosthesis is acceptable.

The slight difference found in stability, support and retention between the genders might be due to the difference in changes in tissue support area. Gender did not bear any effect on the integrity of RPDs, despite greater masticatory forces in males, nor did it have an influence on esthetics and phonetics. Also, no explanation could be given for the difference in rests and rest seats scores between the genders. This may also be related to changes in soft and hard tissues and abutment movement. A slight difference was also noticed in the level of oral hygiene between males and females.

Acceptance of the prostheses was found to be somewhat higher with maxillary RPDs. This could be due to the presence of anterior replaced teeth in the maxillary RPDs; patients may be more likely to be satisfied with their maxillary RPD especially when it involves the esthetic zone. It has also been reported that there is a difference in the frequency of untreated spaces in the maxilla and mandible, with a greater propensity for prosthetic treatment of spaces in the maxilla, likely due to esthetic reasons [36]. Our results indicate that the presence of anterior replacement teeth in maxillary RPDs could increase the acceptance of the prosthesis.

Lower success rates and higher failure scores in adaptation and retention with mandibular RPDs could be due to residual ridge resorption (RRR) in the mandible. Numerous researchers have studied RRR in the maxilla and mandible and there seems to be a general consensus that
RRR is worse in the mandible [37]. One such study found a noticeable reduction of the mandibular alveolar ridge and only a slight reduction of the maxillary alveolar ridge during subsequent years of denture wear [38]. These same authors found the relationship between the mandibular and maxillary reduction to gradually increase to about $4: 1$ at the seven-year stage. It is important to note that the current authors did not include an evaluation of RRR in the maxilla and mandible as part of its criteria, but identifies it as one of the critical factors influencing differences in the success rates between RPDs in the maxilla and mandible. In addition to RRR patterns in the mandible, it has been reported that women have a unique pattern of bone resorption: they have a greater tendency to develop a knife-edge type of mandibular residual ridge due to continuous resorption activity that is pronounced at the labial and lingual surfaces of the residual mandibular alveolar ridge [39]. According to another study females make up the majority of referrals for prosthodontic specialist advice [40]. Moreover, mandibular RPDs have been reported to be associated with retention, stability and relining problems, possibly due to factors such as the muscles in the tongue and floor of the mouth displacing the prosthesis and the decreased surface area of a mandibular RPD [41]. It would therefore appear that there are major obstacles in fabricating a mandibular RPD in female patients with a favorable outcome, a finding reinforced by the results of this study.

Having discussed that RRR appears to affect retention and adaptation, among other things, no explanation could be given as to why the findings suggest that RRR did not have profound effect on RPD stability and support for the study period of this report. Location was not found to have an influence on design, esthetics, and phonetics scores. Also, a slight difference in oral hygiene ratings between the two locations was found in this study.

Outside of the dentist's control are the many patient factors that affect RPD treatment outcomes, including: level of alveolar ridge resorption, quality and quantity of denture bearing oral mucosa, muscles, quality and quantity of saliva, age of the patient and psychological factors, previous denture experience, condition and position of other teeth in the mouth, diet, hygiene, systemic diseases, and others $[32,42,43]$. However, the influence of gender and location are focused on and the results demonstrate some interesting notions. Also of significance are the potential mismatched perceptions and expectations of the patient and dentist and a patient's pre-treatment expectations and attitude toward treatment strongly affects outcomes in dentistry [44-46]. Bearing this in mind and regardless of the gender or location of prosthesis, it is the authors' suggestion that through adequate patient evaluation and education there could be more realistic patient expectations and a resulting improvement in the accep- 
tance of their prosthesis. Hence, there could be a reduction in the failures of this nature resulting in more predictable prosthetic restorations.

\section{CONCLUSION}

The clinical performance of the RPDs showed higher success rates in male patients compared to female patients. Also, the maxillary RPDs showed higher success rates compared to mandibular RPDs. A critical determinant affecting success rates and the difference in success rates was the acceptance (or level of patient satisfaction). Therefore, it would seem that patient factors would be as important, if not more influential, as factors controlled by the practitioner. Practitioners must identify and keep in mind all the factors that affect RPD treatment outcomes. Despite the gender of the patient or the intra-oral location of the prosthesis, the importance of proper treatment planning and proper patient education is emphasized as an essential role of the practitioner. Patients must be educated and made aware of the limitations and shortcomings of RPDs to ensure realistic expectations. If patient expectations and attitudes are realistic, then acceptance of the new prosthesis could be improved, potentially resulting in higher success rates.

\section{ACKNOWLEDGEMENTS}

We would like to thank our patients who volunteered to take part in this study. This study was funded by the University of Saskatchewan.

\section{REFERENCES}

[1] Weintraub, J.A, and Burt, B.A. (1985) Oral health status in the United States: Tooth loss and edentulism. Journal of Dental Education, 49, 368-378.

[2] Douglass, C.W., Shih, A. and Ostry, L. (2002) Will there be a need for complete dentures in the United States in 2020? Journal of Prosthetic Dentistry, 87, 5-8. doi:10.1067/mpr.2002.121203

[3] Douglass, C.W. and Watson, A.J. (2002) Future needs for fixed and removable partial dentures in the United States. Journal of Prosthetic Dentistry, 87, 9-14. doi:10.1067/mpr.2002.121204

[4] Henry, P.J. (2000) Tooth loss and implant replacement. Australian Dental Journal, 45, 150-172. doi:10.1111/j.1834-7819.2000.tb00552.x

[5] Feine, J.S., Carlsson, G.E., Awad, M.A, et al. (2002) The McGill consensus statement on overdentures. International Journal of Prosthodontics, 15, 413-414.

[6] Walton, J.N, Glick, N. and Macentee, M.I. (2009) A randomized clinical trial comparing patient satisfaction and prosthetic outcomes with mandibular overdentures retained by one or two implants. International Journal of Prosthodontics, 22, 331-339.

[7] Walton, J.N, Glick, N., Macentee, M.I. et al. (1998)
Prosthodontic problems and limitations associated with osseointegration. Journal of Prosthetic Dentistry, 79, 7478. doi:10.1016/S0022-3913(98)70197-0

[8] Eckert, S.E., Parein, A., Myshin, H.L., et al. (1997) Validation of dental implant systems through a review of literature supplied by system manufacturers. Journal of Prosthetic Dentistry, 77, 271-279. doi:10.1016/S0022-3913(97)70184-7

[9] Scully, C., Hobkirk, J. and Dios, P.D. (2007) Dental endosseous implants in the medically compromised patient. Journal of Oral Rehabilitation, 34, 590-599. doi:10.1111/j.1365-2842.2007.01755.x

[10] Salinas, T.J., Block, M.S. and Sadan, A. (2004) Fixed partial denture or single-tooth implant restoration? Statistical considerations for sequencing and treatment. Journal of Oral and Maxillofacial Surgery, 62, 2-16. doi:10.1016/j.joms.2004.06.001

[11] Grossmann, Y., Nissan, J. and Levin, L. (2009) Clinical effectiveness of implant-supported removable partial dentures-A review of the literature and retrospective case evaluation. Journal of Oral and Maxillofacial Surgery, 67, 1941-1946. doi:10.1016/j.joms.2009.04.081

[12] Kuzmanovic, D.V., Payne, A.G.T. and Purton, D.G. (2004) Distal implants to modify the Kennedy classification of a removable partial denture: A clinical report. Journal of Prosthetic Dentistry, 92, 8-11. doi:10.1016/j.prosdent.2004.04.010

[13] Uludag, B. and Celik, G. (2006) Fabrication of a maxillary implant-supported removable partial denture: A clinical report. Journal of Prosthetic Dentistry, 95, 19-21. doi:10.1016/j.prosdent.2005.10.021

[14] Mojon, P., Rentsch, A. and Budtz-Jorgensen, E. (1995) Relationship between prosthodontic status, caries, and periodontal disease in a geriatric population. International Journal of Prosthodontics, 8, 564-571.

[15] Kapur, K.K., Deupree R., Dent R.J., et al. (1994) A randomized clinical trial of two basic removable partial denture designs. Part I: Comparisons of five-year success rates and periodontal health. Journal of Prosthetic Dentistry, 72, 268-282 doi:10.1016/0022-3913(94)90340-9

[16] Vanzeveren, C., D’Hoore, W., Bercy, P., et al. (2003) Treatment with removable partial dentures: A longitudinal study. Part I. Journal of Oral Rehabilitation, 30, $447-$ 458. doi:10.1046/j.1365-2842.2003.01106.x

[17] Frank, R.P., Brudvik, J.S., Leroux, B., et al. (2000) Relationship between the standards of removable partial denture construction, clinical acceptability, and patient satisfaction. Journal of Prosthetic Dentistry, 83, 521-527. doi:10.1016/S0022-3913(00)70008-4

[18] Wostmann, B., Budtz-Jørgensen, E., Jepson N., et al. (2005) Indications for removable partial dentures: A literature review. International Journal of Prosthodontics, 18, 139145.

[19] Shah, N. (2003) Gender issues and oral health in elderly Indians. International Dental Journal, 53, 475-484. doi:10.1002/j.1875-595X.2003.tb00890.x

[20] Zlatarić, D.K., Čelebić, A., Valentić-Peruzović, M., et al. (2003) A survey of treatment outcomes with removable 
partial dentures. Journal of Oral Rehabilitation, 30, 847854. doi:10.1046/j.1365-2842.2003.01039.x

[21] Jepson, N.J., Thomason. J.M. and Steele, J.G. (1995) The influence of denture design on patient acceptance of partial dentures. British Dental Journal, 178, 296-300. doi:10.1038/sj.bdj.4808742

[22] Jeffreys, F.E. and Platner, R.L. (1960) Occlusion in removable partial dentures. The Journal of Prosthetic Dentistry, 10, 912-920. doi:10.1016/0022-3913(60)90125-6

[23] Colman, A.J. (1967) Occlusal requirements for removable partial dentures. The Journal of Prosthetic Dentistry, 17, 155-162. doi:10.1016/0022-3913(67)90030-3

[24] Carr, A.B. and Brown, D.T. (2011) Principles of removable partial denture design. In: McCracken's Removable Partial Prosthodontics, 12th Edition. Elsevier Mosby, St. Louis, 115-129. doi:10.1016/B978-0-323-06990-8.00010-5

[25] Wakabayashi, N., Yatabe, M.A.M., Sato, M., et al. (1998) The influence of some demographic and clinical variables on psychosomatic traits of patients requesting replacement removable partial dentures. Journal of Oral Rehabilitation, 25, 507-512. doi:10.1046/j.1365-2842.1998.00264.x

[26] Van Waas, M.A.J. (1990) The influence of psychologic factors on patient satisfaction with complete dentures. Journal of Prosthetic Dentistry, 63, 545-548. doi:10.1016/0022-3913(90)90073-L

[27] Van Waas, M.A.J. (1990) Determinants of dissatisfaction with dentures: A multiple regression analysis. Journal of Prosthetic Dentistry, 64, 569-572. doi:10.1016/0022-3913(90)90130-5

[28] Van Waas, M.A.J. (1990) The influence of clinical variables on patients' satisfaction with complete dentures. Journal of Prosthetic Dentistry, 63, 307-310. doi:10.1016/0022-3913(90)90202-N

[29] Carr-Hill, R.A. (1992) The measurement of patient satisfaction. Journal of Public Health Medicine, 14, 236-249.

[30] Hakestam, U., Söderfelt, B., Rydén, O., et al. (1997) Dimensions of satisfaction among prosthodontic patients. European Journal of Prosthodontics Restorative Dentistry, 5, 111-117.

[31] Watson, C.L., Reeve, P.E., Barnes, E., et al. (1986) The role of personality in the management of partial dentures. Journal of Oral Rehabilitation, 13, 83-91. doi:10.1111/j.1365-2842.1986.tb01558.x

[32] Wong, M.M.L., Ettinger, R. and Barsby, M.J. (1995) An evaluation of removable partial dentures: A retrospective study. Iowa Dental Journal, 81, 13-16.

[33] Langer, A., Michman. J. and Seifert, I. (1961) Factors influencing satisfaction with complete dentures in geriatric patients. The Journal of Prosthetic Dentistry, 11, 10191031. doi:10.1016/0022-3913(61)90038-5

[34] Carlsson, G.E., Otterland, A. and Wennström, A. (1967)
Patient factors in appreciation of complete dentures. The Journal of Prosthetic Dentistry, 17, 322-328. doi:10.1016/0022-3913(67)90002-9

[35] Youssef, R.E., Throckmorton, G.S., Ellis, E., et al. (1997) Comparison of habitual masticatory patterns in men and women using a custom computer program. Journal of Prosthetic Dentistry, 78, 179-186. doi:10.1016/S0022-3913(97)70123-9

[36] Battistuzzi, P., Kayser, A. and Kanters, N. (1987)) Partial edentulism, prosthetic treatment and oral function in a Dutch population. Journal of Oral Rehabilitation, 14, 549555. doi:10.1111/j.1365-2842.1987.tb00751.x

[37] Klemetti. E. (1996) A review of residual ridge resorption and bone density. Journal of Prosthetic Dentistry, 75, 512-514. doi:10.1016/S0022-3913(96)90455-2

[38] Tallgren, A. (1972) The continuing reduction of the residual alveolar ridges in complete denture wearers: A mixed-longitudinal study covering 25 years. The Journal of Prosthetic Dentistry, 27, 120-132. doi:10.1016/0022-3913(72)90188-6

[39] Nishimura, I., Hosokawa, R. and Atwood, D.A. (1992) The knife-edge tendency in mandibular residual ridges in women. The Journal of Prosthetic Dentistry, 67, 820-826. doi:10.1016/0022-3913(92)90592-X

[40] Yemm, R. (1985) Analysis of patients referred over a period of five years to a teaching hospital consultant service in dental prosthetics. British Dental Journal, 159, 304306. doi:10.1038/sj.bdj.4805715

[41] Hummel, S.K., Wilson, M.A., Marker, V.A., et al. (2002) Quality of removable partial dentures worn by the adult US population. Journal of Prosthetic Dentistry, 88, 37-43.

[42] Cowan, R.D., Gilbert, J.A., Elledge, D.A., et al. (1991) Patient use of removable partial dentures: Two- and four-year telephone interviews. The Journal of Prosthetic Dentistry, 65, 668-670. doi:10.1016/0022-3913(91)90204-A

[43] Petridis, H. and Hempton, T.J. (2001) Periodontal considerations in removable partial denture treatment: A review of the literature. International Journal of Prosthodontics, 14, 164-172.

[44] Albino, J.E., Tedesco, L.A. and Conny, D.J. (1984) Patient perceptions of dental-facial esthetics: Shared concerns in orthodontics and prosthodontics. The Journal of Prosthetic Dentistry, 52, 9-13. doi:10.1016/0022-3913(84)90172-0

[45] Weinstein, M., Schuchman, J., Lieberman, J., et al. (1988) Age and denture experience as determinants in patient denture satisfaction. The Journal of Prosthetic Dentistry, 59, 327-329. doi:10.1016/0022-3913(88)90184-9

[46] Diehl, R.L., Foerster, U., Sposetti, V.J., et al. (1996) Factors associated with successful denture therapy. Journal of Prosthodontics, 5, 84-90. doi:10.1111/j.1532-849X.1996.tb00279.x 